\title{
Análisis de los efectos que produce el sufrimiento institucional en sujetos privados de la libertad. ${ }^{1}$
}

\section{Analysis of the effects that produces the institutional suffering in subjects deprived of the freedom.}

\author{
Georgina Elsa Borzone ${ }^{2}$
}

\section{Resumen}

Este artículo se propone transmitir la experiencia de trabajo realizada en un dispositivo interdisciplinario de salud en una institución carcelaria. Con el propósito de analizar cómo incide la cárcel, entendida como institución total en procesos de desubjetivación, se analizarán dos tiempos de trabajo distinto. Por un lado, un momento en el que los sujetos se encuentran sumergidos en la dinámica institucional. Allí se situarán tres vías que la institución propone y que inciden en la obturación de la emergencia del sujeto del inconsciente. Por otro lado, se situarán efectos que aparecen en el discurso de los sujetos en los momentos en los que la puerta se abre y con ello aparece la posibilidad de apertura de lo psíquico.

\section{Palabras clave \\ Psicoanálisis - Instituciones - Cárceles - Sufri- miento institucional}

\section{Abstract}

This article aims to transmit the experience of work carried out in an interdisciplinary device of health inside a prison. With the in- tention of analyzing how prison, understood as a total institution, affects people through processes of desubjectivation. The analysis will be considered in two different stages of the work. Firstly, the moment in which the subjects are immersed in the institutional dynamics. There we will see three ways proposed by the institution which affect and obture the emergency of the unconscious subject. Secondly, there will be other effects that appear in the stories told by subjects in the very special moment in which the door opens and it appears the possibility of mental opening.

Keywords:
Psychoanalysis - Institutions - Prison - Institu-
tional Suffering

\section{Introducción}

En base a la experiencia de trabajo transitada como psicóloga integrante de un equipo de salud en el ámbito penitenciario, se situarán vías para analizar cómo incide la cárcel, entendida como institución total (Goffman, 2007) en el detenimiento de ciertas producciones psí-

\footnotetext{
${ }^{1}$ El presente artículo fue reescrito sobre la base del Trabajo Final Integrador de la Carrera de Especialización en Psicología Clínica, Institucional y Comunitaria "Dificultades de la clínica psicoanalítica en una institución total" del que soy autor y que fue dirigido por la Psa. Adriana Covili.

${ }^{2}$ Georgina Elsa Borzone, integrante de Dispositivo Interdisciplinario de Salud en el ámbito del Servicio Penitenciario. Dirección Provincial de Salud Mental. Ministerio de Salud de la Provincia de Santa Fe. Psicóloga y Profesora en Psicología (UNR). Especialista en Psicología clínica, institucional y comunitaria(UNR). Rosario. República Argentina. georginaborzone@hotmail.com
} 
quicas de los sujetos, fundamentalmente lo que Freud (1900) llamó la "vía regia de acceso al inconsciente" (p.63) los sueños, por un lado y la emergencia de la angustia por el otro.

La institución total se erige instalando un "orden de hierro" (Lacan, 1977), vedando toda posibilidad de elegir o decidir y de esa manera impide la emergencia del sujeto del inconsciente, por consecuencia el ordenamiento que la cárcel impone no produce responsabilidad.

Para los fines de este escrito se tomarán dos tiempos de trabajo distinto. Un primer momento hará hincapié en el desarrollo de la tarea en una institución penitenciaria en la que los detenidos están en el primer tramo de la condena. Es decir, que no tienen posibilidad de gozar de algunos de los beneficios que enuncia la ley $\mathrm{N}^{\circ} 24660^{3}$. Aquí la institución permanece a puerta cerrada y se impone transitar la pregunta: ¿de qué modo lo institucional atraviesa el discurso?

Podemos encontrar una pista en el siguiente testimonio: Un sujeto que, luego de estar varios años detenidos en una unidad penitenciaria, sin tener ningún tipo de salida, conoce a una mujer que se acerca un día de visitas al penal y comienza a tener una relación de pareja con ella. Este hecho despierta la siguiente reflexión: "Ni me pregunto lo que es ella para mí. Es lo que hay, es la que vino, el preso no elige".

${ }^{3}$ Ley de ejecución de la pena privativa de la libertad (Ley 24 660). Sancionada en el año 1996. Capítulo II. Modalidades Básicas de Ejecución. Sección primera. Progresividad del régimen penitenciario. Períodos. El régimen penitenciario aplicable al condenado, cualquiera fuera la pena impuesta, se caracterizará por su progresividad y constará de: a) Periodo de observación; b) Período de tratamiento; c) Periodo de prueba, d) Periodo de libertad condiconal.

Salidas transitorias: 16- Las salidas transitorias, según la duración acordada, el motivo que las fundamente y el nivel de confianza que se adopte podrán ser: Por el tiempo a) Salidas hasta doce horas; b) Salidas veinticuatro horas; c) Salidas, en casos excepcionales, hasta setenta y dos horas. Por el motivo a) Para afianzar y mejorar los lazos familiares y sociales, b) Confiando la tuición de un familiar o persona responsable; c) Bajo palabra de honor.
Identificamos un segundo momento en la institución cuando un número importante de las personas detenidas pueden acceder a las salidas transitorias. Aquí los interrogantes se reformulan: ¿qué sucede cuándo súbitamente desaparece el camino marcado por el otro?

La apertura de la puerta, en tanto irrupción de lo real, es algo que impone ser simbolizado o imaginarizado a partir de la indagación de los efectos que produce en los sujetos la amenaza de algo del orden de la libertad.

El mismo sujeto, que cuando la institución se encontraba a puerta cerrada, reflexionaba con cierto alivio que por "ser preso no elige mujer", al tener una salida transitoria, se dirige a encontrarse con la mujer que le tocó, y en el trayecto se encuentra con una mujer que le gusta mucho. Este hecho le provoca una serie de dudas e interrogantes que le permiten hablar de sus fantasías, deseos y gustos que al parecer solo se ponen en juego cuando existe la posibilidad de elegir.

A partir del análisis del discurso de los consultantes al Dispositivo de Salud Mental, ubicado en una cárcel, se indagarán tres vías que la institución total encuentra y que producen como efecto distintos modos de desubjetivación. La elección de estas vías se debe a que son las que más resuenan en la palabra de los que padecen día a día el encierro y el cumplimiento de la pena, esa aplicación diaria de determinada cuota de dolor. Esta elección, no obstante, no pretende agotar la problemática que aquí nos convoca.

Las vías propuestas que obstaculizan la aparición de un sujeto deseante son:

- El disciplinamiento provocado por la mirada panóptica.

- La libertad como ideal.

- Los "quita pena" ubicados en la intoxicación y la religión.

Si hay un lugar en el que el sujeto va a tener garantizado el sufrimiento, es en una cárcel. Estamos en el terreno de la mudez, de un padecer impersonal, silente, que hace que el 
sujeto no se sienta culpable de nada. La cárcel es un lugar que alimenta el masoquismo moral patológico, garantizando que cada día se tendrá una cuota de sufrimiento, exorcizando a los sujetos que están sumergidos en la vida institucional de transitar al menos sentimientos engañosos como la culpa. En este sentido recorreremos el artículo de Freud (1924) "El problema económico del masoquismo".

La hipótesis horizonte de este escrito es que la institución total, impide el surgimiento de la angustia, síntomas e inhibiciones.

Para trabajar la hipótesis arriba mencionada nos ubicaremos desde lo que fue llamado por los investigadores de la historia como paradigma indiciario (Cancina, 2008). Analizando la información surgida del análisis de viñetas clínicas, dichos y expresiones de los consultantes al Dispositivo Interdisciplinario de Salud en el ámbito del Servicio Penitenciario

La indagación de esta problemática conlleva un doble interés. Un interés clínico, ligado a la pregunta por los elementos que tienen que estar en juego para el surgimiento de la angustia, para el advenimiento de alguna interrogación que interpele al sujeto: ¿es posible la emergencia de la angustia cuando las posibilidades de elegir están restringidas?

Por otro lado, un interés que pretende aportar a las políticas en salud y en particular de salud mental, dado que para que exista salud, tiene que existir algún nivel de la libertad y que la recuperación de alguien con padecimiento mental tiene que ser pensada en relación con la comunidad y evitando propuestas segregacionistas o expulsivas.

\section{Institución total y vulneración de los sujetos}

Cuando la institución permanece a puerta cerrada, la relación de los sujetos que permanecen sumergidos en la dinámica institucional con el lenguaje se presenta de un modo monolítico y monocorde. La vida en este universo artificial que es la cárcel produce que determinados temas o conflictos se interrumpan. Si el contacto con el mundo exterior es escaso, los problemas que de él devienen se disuelven. La consecuencia de esa coagulación que se produce en el plano de la palabra es la disminución de afectos engañosos, como la culpa y el impedimento de la emergencia del único afecto que no engaña: la angustia (Lacan, 1963). Aquellos elementos que ponen a punto el síntoma en el sentido psicoanalítico y que permiten que estemos en condiciones de plantear un tratamiento posible son sofocados y trastocados en sufrimiento institucional, un sufrimiento silente, mudo.

La institución total, actúa eficazmente en su modo de acallar a los sujetos y lo hace por diferentes vías. A los fines de este trabajo, se seleccionarán las tres que más insisten en el armado discursivo de los sujetos que habitan este espacio institucional.

\section{El disciplinamiento:}

Se entiende a la institución carcelaria como productora de una fuerte intervención en el tiempo y el espacio, lo que produce un estado de detenimiento, absorbiendo la cotidianeidad de los sujetos que están allí alojados. Es la institución la que se encarga de administrar los horarios para comer, define qué es lo que se come, cuándo se tiene una visita, a qué hora y dónde se duerme, imponiendo uniformidad mediante la homogeneización. Es un momento de suspensión de todo orden de decisión en el que las posibilidades de elegir son limitadas o vedadas.

A puerta cerrada se construye un universo artificial, en el que abundan las imágenes que persisten: rejas, grilletes, uniformes, tatuajes y frases que, de tanto insistir, comienzan a desoírse.

En el plano del sufrimiento institucional no hay lugar para la emergencia de la angustia, es 
un ordenamiento ortopédico a modo de respuesta que detiene las preguntas. La institución total avanza sobre los aspectos íntimos, desaparece el pudor, todo es visto por todos, al mismo tiempo que se mutilan aspectos que hacen a la identidad. En la cárcel, el número de matrícula reemplaza al nombre propio, en ocasiones, y al documento de identidad siempre, La mirada panóptica, implica a otro omnivoyeur que deja al sujeto sin disfraz posible, sin escansión. Nada que velar.

Los relatos que expresan los sujetos privados de la libertad, anclan en la palabra y dejan marcas en el cuerpo, hacen que esta experiencia de privación que debería ser transitoria se fijen en identidad que atraviesa muros: "el preso es así”, "el preso no elige", "el preso tiene que aprender a pelear por lo suyo", "soy tumbero" 4

La institución total produce como efecto que el síntoma se cierre de manera defensiva sobre sí mismo, lo que en la calle puede ser sintomático aquí es identidad que permite sobrevivir.

Fernando Ulloa (1995), en Novela clínica psicoanalítica, decía que una misma institución puede resultar total o abierta para alguien y que lo que define qué es una institución para una persona, no está dado por lo que alguien hace en ese lugar (comer, dormir, jugar, etc.) sino cuando la institución pasa a ser el centro organizador de la vida, es decir, si la misma se configura en dadora de identidad para alguien.

En términos de J. Lacan (1974), referimos a un "orden de hierro" que produce nominación fallida, aquello que hace signo, en tanto el "ser nombrado para" sustituye el Nombre del Padre y restituye un orden que es de hierro. "El preso es así" pero también "no cambio más, siempre voy a ser un delincuente", "soy

\footnotetext{
${ }^{4}$ Todos los testimonios encomillados sin referencias presentes en el texto corresponde a expresiones de los sujetos consultantes al Dispositivo Interdisciplinario de Salud y son producto del trabajo clínico.
}

una rata".

Se advierte que la "salida transitoria" es un elemento que viene a fisurar lo totalizante en la medida en que puede vertebrarse una pregunta: "Ahora que estoy por salir, pienso que voy a cambiar, recuerdo que cuando era niño soñaba con ser mecánico, mi problema fue la adolescencia, no sé lo que pasó...¿Podré estudiar algo? No un curso, me gustaría hacer una carrera larga, de esas que hacen que te miren distinto, abogacía, ingeniería...pero son difíciles ¿Usted que dice, puedo hacer algo difícil?”

\section{La libertad como ideal:}

Quien está dentro de una prisión no está atravesado por el ideal resocializador, ni aquellos que están detenidos, ni aquellos que están allí trabajando, en tanto el llamado ideal de resocialización es algo que solo puede tocar a aquellos que jamás ingresaron a una cárcel. Es nulo el porcentaje de las personas entrevistadas en el interior del penal que consideren que esta experiencia tenga algún horizonte interesante o algo que valga la pena, en cambio de un lado y otro de la reja la experiencia de transitar por un penal es algo que "se soporta", las actividades son realizadas "para matar el tiempo", "para despejarse la mente", "para aguantar".

Los ideales que motorizan el accionar diario son trocados por ideales coagulados de sentido, que se expresan en frases enunciadas metonímicamente, sin que los sujetos puedan encontrar un anclaje que les permita apropiarse o darle un valor para sí mismos "cuándo salga voy a tener un trabajo, tener una familia y una casa en el campo".

La apuesta clínica queda ligada a producir un intersticio en ideales que se presenten como latiguillos y acompañar a los sujetos a que puedan construir un proyecto de vida.

"Ahora no me preocupa el tema porque estoy acá preso y otra no queda, pero cuando salga, voy a dejar de drogarme", expresa un 
consultante, que al comenzar con las salidas transitorias, se encuentra con que esta tarea de "dejar de drogarse" va a requerir un trabajo arduo que implica renuncia y oposición a la oferta del entorno ya que en sus palabras "todos los que conozco afuera se drogan". El trabajo postergado en el encierro, exige ser afrontado en el afuera, las salida transitoria lo pone en contacto con preguntas que trae al volver al penal, averigua a donde puede recurrir y reflexiona respecto de que a él siempre le costó pedir ayuda "siempre quise hacerme solo" ya que "no se puede confiar en nadie".

\section{Los quita pena:}

La cárcel produce un tratamiento particular de las penas y del sufrimiento o se las quita o se las refuerza mediante una inserción colectiva y religiosa.

El dogma dirige la palabra, congela el discurso y se hace destino de vida: "Estoy preso porque Dios lo quiere", "bienaventurados los que sufren", "no voy a morir porque Dios no quiere que muera". "A veces uno quiere estar bien, pero aparece el diablo y te mete los malos pensamientos. El diablo te hace pensar cosas malas". "Si Dios quiere, Él te puede hacer inmortal, yo, estoy como resignado, voy a sufrir siempre", "Dios te ama".

En los llamados pabellones evangélicos, cada día comienza orando desde temprano en la mañana, cantando, aplaudiendo y alabando al Señor. Se reza y se pide "que Dios aleje los malos pensamientos", "saque las ganas de hacer maldades" o se "pide perdón por apartarse del camino de Dios". La religión produce un reforzamiento del sufrimiento y del sentímiento de culpa.

Otro modo de quitar las penas es por la vía de la intoxicación. Los consultantes expresan "se te pasa el tiempo", "te ayudan a soportar el encierro", "que voy a dejar de drogarme ahora si estoy preso, cuando salga..."

Para los fines de este trabajo, elegimos un párrafo de Freud (1924) El problema económico del masoquismo: "Si dolor y displacer pueden dejar de ser advertencias para constituirse, ellos mismos en metas, el principio del placer queda paralizado, y el guardián de nuestra vida anímica, por así decirlo narcotizado” (p.165).

\section{Sufrimiento silente:}

Encontramos una clara definición de lo que es la vida en el encierro relatada por otro sujeto que pasó gran parte de su vida detenido en instituciones penitenciarias. En sus dichos, no se encuentra que el encierro haya provocado en él preguntas respecto de su responsabilidad, ya que en sus palabras: "me la pasé preso por mala suerte". Lejos de convocar preguntas, este sujeto expresa su situación del siguiente modo: "acá me olvido de mi propia vida, con los presos me olvido de lo que sufrí, acá solo tengo que pensar en pagar la condena". Estar pagando una condena elide toda posición subjetivante respecto de la deuda y la culpa.

La institución a puerta cerrada perpetúa el masoquismo moral patológico del que habla Freud (1924). En él, va a decir que la aspiración masoquista en la vida pulsional está mediatizada por fantasías.

El masoquismo se ofrece a nuestra observación en tres figuras:

- Como condición a la que se sujeta la excitación sexual, masoquismo erógeno

- Como una expresión de la naturaleza femenina, masoquismo femenino.

- Como una norma de conducta en la vida, masoquismo moral.

Masoquismo erógeno o primario: el gusto de recibir dolor, está en el fundamento de las otras dos formas, por lo cual masoquismo erógeno es testigo y remanente de la mezcla pulsional, de aquella fase de formación en la que aconteció la liga, tan importante para la vida entre Eros y Thánatos. Es un subrogado de la pulsión de muerte que se liga al desarro- 
llo de la libido en las distintas fases del desarrollo hasta la organización genital definitiva. Así, las pulsiones parciales se van intrincando en las distintas fases del desarrollo, en tanto que el masoquismo erógeno toma prestados sus cambiantes revestimientos psíquicos. Este masoquismo primario como superestructura psíquica no sólo está implicado en toda la constitución subjetiva, sino que el mismo habrá de suponer tiempos de constitución, de una articulación de un espacio fantasmático, en el que culpa y erotismo se anuden en relación al padre.

El masoquismo erógeno está en el fundamento de todo masoquismo y es entendido como constitutivo. Dependerá de este tiempo de constitución subjetiva el que pueda derivar en masoquismo femenino o masoquismo moral, como norma de conducta en la vida.

Masoquismo moral: Es notable por haber aflojado su vínculo con la sexualidad, entonces se hace más Thanático, estamos en el campo de lo patológico. El padecer, en masoquismo moral, se hace impersonal, en los casos extremos podemos suponer el puro sufrimiento, el padecimiento es padecimiento en sí.

Freud (1924) entonces comienza a desarrollar el punto más extremo que es la "forma patológica del masoquismo moral", donde aparece:

Padecer impersonal; Sentimiento inconsciente de culpa, es decir allí donde el sujeto no se siente culpable. "No se sienten culpables de nada". Este desenlace de la ley de la palabra implica un gran monto de satisfacción como ganancia de enfermedad, satisfacción muda que hace que el síntoma se cierre sobre sí mismo en un "puro padecer". El resultado de esto será la reacción terapéutica negativa por un sentimiento inconsciente de culpa cuya satisfacción es ganancia de enfermedad.

Freud (1924) va a advertir que es incorrecto emplear la denominación "sentimiento inconsciente de culpa", ya que los sentimientos no son inconscientes y lo llamará necesidad de castigo, necesidad de ser castigado por el poder parental.

El deseo de ser golpeado por el padre, $\tan$ frecuente en las fantasías, está relacionado con otro deseo, el de entrar con él en una vinculación sexual pasiva (femenina) y no es más que una desfiguración regresiva de éste último. Entonces, si referimos este esclarecimiento al contenido del masoquismo moral, se nos vuelve evidente su secreto sentido.

La conciencia moral y la moral misma nacieron de la superación, la desexualización del complejo de Edipo; mediante el masoquismo moral la moral es resexualizada, el complejo de Edipo reanimado, se abre la vía para una regresión de la moral al complejo de Edipo.

Esto no va a redundar en beneficio de la moral ni del individuo y es posible que en el masoquismo "naufrague buena parte de la consciencia moral" (Freud, 1924. p175). El naufragio de la conciencia moral crea la tentación de un obrarpecaminoso que luego tiene que ser expiado, y esto puede suceder por algunas de las siguientes vías:

reproches de la conciencia moral sádica;

con el castigo del destino, ese gran poder parental. (Para provocar el castigo el masoquista se ve obligado a hacer cosas inapropiadas, a trabajar en contra de su beneficio) o bien; se afloja el vínculo con la fantasía y la posibilidad de construcción fantasmática, constituyéndose una muda culpabilidad, no estamos en el plano de la culpa subjetivada.

La peligrosidad del masoquismo moral patológico, como norma de conducta de la vida, se debe a que desciende de la pulsión de muerte. Este resto se ha sustraído a su vuelta hacia afuera como pulsión de destrucción. Al tener el valor psíquico de un componente erótico, ni aún la destrucción de la persona puede producirse si satisfacción libidinosa.

Un penal garantiza sufrimiento y cuota de dolor diario. Para cumplir con una condena, se rebajan afectos neuróticos como la culpa. La institución total se configura como un lu- 
gar en el que se satisface el masoquismo moral patológico, garantizando que cada día se tendrá una cuota de sufrimiento. Se alimenta ese padecer, silente, mudo que hace que el sujeto no se sienta culpable de nada. Recordemos el "estoy preso por mala suerte".

La apuesta clínica tiene que ver con la posibilitar a cada sujeto salir de la mudez, producir apertura discursiva e interrogación. El trabajo no tiene que ver con intentar que alguien se sienta culpable. Intentar algo en esa vía sería como creer en la inocencia. La direccionalidad está del lado de producir un pasaje de la lógica culpa- castigo al incauto del inconsciente, esto es, sintomatizar la pregunta.

"Acá me olvido de mi propia vida", como frase monolítica, es fisurada cuando aparecen elementos que interrogan la vida en el afuera. Allí aparece la posibilidad de apertura discursiva, recuerdos, temores, nostalgias, frustraciones y la posibilidad abierta a la emergencia de la angustia.

\section{La posibilidad de elegir como condi- ción para vivir}

Como los efectos más llamativos de la vida en el encierro, se advierte el detenimiento de la posibilidad de soñar, el reemplazo del sueño por pesadilla o por ideas que dificultan el acto de dormir. Las palabras de los sujetos privados de la libertad, resuenan del siguiente modo: "no tengo sueños, tengo pensamientos", "soñé que me daban cinco puñaladas", "soñé que mataban a mi hermano", "yo no sueño", "a la noche me cuesta dormir porque se me vienen muchas ideas a la mente, tengo miedo de quedarme colgado con la reja".

En Gerez Ambertín (2007) encontramos que en los sueños punitorios, al cortarse la trama asociativa, se diluye el mensaje cifrado y la estructura del lenguaje, por tanto se eclipsa el deseo y de ahí la pesadilla, el golpe de angustia y el insomnio resultante.

Las salidas transitorias, la inminencia de la apertura de la puerta, son un elemento que interrumpe esa maquinaria puesta al servicio de pensar y decidir por el otro.

Ante la inminencia de la apertura de la puerta, algo comienza a ponerse en marcha, los sujetos comienzan a relatar sueños, temores, recuerdan la dificultad de vivir en el afuera, ligada fundamentalmente a la posibilidad de elegir.

El silencio superyoico impide el advenimiento de la palabra. La apuesta clínica queda ligada del lado de instalar un enigma en el sujeto que les permita hablar, soñar, despertar.

\section{Conclusiones}

En los muros de la cárcel quedan aplanadas las subjetividades. Estar detenido, soportar el encierro, matar el tiempo, pensar en cumplir una condena, son actividades que se sostienen pagando altos costos: interrumpir la vida onírica, clausurar preguntas, elidir responsabilidades, eyectar la angustia y degradar la responsabilidad en culpa.

Aquí situamos, distintas vías que la institución carcelaria encuentra para obturar la emergencia del sujeto del inconsciente. Mediante estos caminos la institución produce sufrimiento institucional, mudo, silente en el que se alimenta aquello que Freud (1924) ubicó como narcisismo moral patológico, un padecer impersonal que alimenta la necesidad de castigo.

En el plano del sufrimiento aparecen los ideales institucionales, las nominaciones fallidas que fijan al sujeto en una identidad única, el discurso monolítico y la posibilidad de anestesiar la angustia mediante la intoxicación y la religión.

La cárcel propone un universo artificial en el que se suspende todo orden de decisión, ofrece un disciplinamiento homogenizante en el que se obtura la pregunta y la interrogación.

"Perdí todo", es una frase que se escucha con recurrencia en los relatos de los sujetos 
privados de la libertad. La apuesta es a que puedan encontrar palabras que definan qué es ese todo para ese sujeto en particular. Elegir es un acto que resulta de la posibilidad de perder o renunciar a algo. Los relatos de los sujetos que están privados de la libertad, nos muestran como por no perder algo lo pierden todo.

La vida humana emerge como resultado de operatorias, ligadas al corte, a la alternancia, a elecciones que son el resultado de renuncias, lo que ocurre en un universo aparentemente continuo total y carente de escansiones queda ligado al terreno de la supervivencia.

La institución total alimenta un estado ficcional al que es posible definir como de pura pérdida: el tiempo parece no pasar, las rejas parecen siempre igual, las frases se repiten de un modo casi invariable.

La inminencia de la apertura de la reja, que se produce cuando los sujetos tienen la posibilidad de salir del penal, por condena cumplida o por salidas transitorias, es un elemento de ruptura de lo totalizante. En este punto comienza otro tipo de apuestas clínicas, ligadas a que un sujeto pueda vertebrar una pregunta, a horadar el orden de hierro, a captar las producciones del inconsciente que se abren junto a la reja.

Desde el espacio de consultas con perspectiva psicoanalítica se intenta acompañar a que los sujetos puedan dar palabras al sufrimiento provocado por la vida en el encierro y también a que puedan estar advertidos de los efectos de las salidas transitorias.

En un penal la libertad se presenta como un ideal cristalizado, lograr acceder a una salida transitoria es una noticia que se recibe con un monto de excitación y felicidad y muchas veces los problemas que devienen de la vida en el afuera toman por sorpresa a los sujetos que padecieron largos años el encierro.

Se encuentra una relación entre las posibilidades de elaborar y de estar atentos a los efectos que tiene el contacto con el afuera con la posibilidad de sostener el régimen de salidas transitorias, lo que conduce a resolver la situación penal.

Decididamente la implicancia es una operatoria ligada a un trabajo de interrogación, de preguntas y renuncias que requiere de un terreno de escucha y de elecciones que se producen con algún nivel de libertad.

\section{Referencias:}

- ARANDA DIAZ,E. GIMBERNAT ORDEIG, E. JÄGER,C. ROXIN, C. Problemas fundamentales de politica criminal y derecho penal. Visita 1 agosto de 2017.En http://www.cubc.mx/biblioteca/libros

- COVILI, ADRIANA. (2004) Usted pensará que soy un delincuente pero esa no es mi naturaleza. Trabajo presentado en XI Jornadas de Psicoanálisis Sigmund Freud- Rosario "El psicoanálisis se reinventa cada vez". Edición digital http//www.compopsi. com/Epsfros.

- $\quad$ FREUD, SIGMUND. (2007) El yo y el ello $y$ otras obras (1923-1925). Buenos Aires. Argentina. Amorrortu Editores

- GEREZ, AMBERTÍN MARTA. (2007) Las voces del super yo. En la clínica psicoanalítica y en el malestar en la cultura. Buenos Aires. Argentina Letra Viva.

- GOBIERNO DE LA PROVINCIA DE SANTA FE. MINISTERIO DE SEGURIDAD. SECRETARÍA DE ASUNTOS PENITENCIARIOS (2008). Hacia una política progresista básica en la provincia de Santa Fe.

- GOFFMAN, ERVING (2007). Internados. Ensayos sobre la situación social de los enfermos mentales. Buenos Aires. Argentina. Amorrortu.

- LACAN, JAQUES (2008). La angustia. Seminario 10 (1962-1963). Buenos Aires. Argentina. Paidós.

- LACAN, JAQUES. Los desengañados se engañan. Seminario 21 (1973-1974). Inédi- 
to. (Impreso para circulación interna de la Escuela Freudiana de Buenos Aires. Buenos Aires. 1977

- 10772/91. LEY DE SALUD MENTAL. LEGISLATURA DE LA PROVINCIA DE SANTA FE. 26 DE DICIEMBRE 1991.
- LEY 24 660. LEY DE EJECUCIÓN DE LA PENA PRIVATIVA DE LA LIBERTAD. 8 DE JULIO DE 1996

- UlloA, FERNANDO (1995). Novela clínica psicoanalitica. Historial de una práctica. Buenos Aires. Argentina. Editorial Paidós. 